\title{
Foreword: Toward a Quantitative Understanding of the Frontier in Geothermal Energy
}

\author{
Klaus Regenauer-Lieb ${ }^{1,2,3}$, David A. Yuen ${ }^{4,5}$, Shihua Qi ${ }^{4}$, Yanxin Wang ${ }^{4}$, Chisheng Liang $^{6}$ \\ 1. School of Petroleum Engineering, University of New South Wales, Sydney NSW 2052, Australia \\ 2. Earth Science and Resource Engineering, CSIRO, Kensington WA 6151, Australia \\ 3. School of Earth and Environment, The University of Western Australia, Perth WA 6000, Australia \\ 4. School of Environmental Studies, China University of Geosciences, Wuhan 430074, China \\ 5. Department of Earth Sciences and Minnesota Supercomputing Institute, University of Minnesota, Minneapolis MN 55455, USA \\ 6. Guangdong Geological Bureau, Guangzhou 510080, China
}

Our planet, Earth, contains an enormous amount of heat just right under our feet. Harnessing this heat from 2 to $5 \mathrm{~km}$ below is one of the great challenges of the 21 st century, because this can solve many of the currently urgent problems in mega-cities, such as inexpensive domestic heating and airconditioning, electric power consumption and the cure of rampant air pollution. Around $40 \mathrm{TW}$ heat are released at a steady rate by the Earth partly due to natural radioactive decay and partly due to the action inside the core. We would like to stress here that the depth of the isotherm of $200{ }^{\circ} \mathrm{C}$ (minimum temperature for efficient generation of electricity) varies around the globe. In general, this depth would be less than $10 \mathrm{~km}$ deep. Therefore these heat sources would provide ubiquitous ample, clean and sustainable electricity. In addition to this sustainable resource the potential of geothermal energy use is much greater, because it allows effective heat mining of the Earth. Geothermal energy is most commonly exploited in volcanic areas where magma is close to the surface and brings up the heat from deeper down. The largest geothermal power plant of this style is the Geysers in California, which with $1 \mathrm{GW}$ power production rivals nuclear power plants.

Other more unconventional uses of geothermal energy are currently being proposed and described in this volume, such as new low-cost drilling technology by utilizing novel physical principles, for example electric-pulse-boring or ionic plasma. The most easily attainable target for geothermal energy is using natural hot underground water motions in sedimentary basins to take advantage of high porosity and permeability. By advancing science and technology in such lowtemperature geothermal systems, direct heat applications are the most profitable target. This implies using geothermal energy right where it is needed while contributing to making alternative energy competitive locally and globally. Because of the cultural awareness of heat as a commodity, China is already leading the world in current direct heat usage but China still has a lot of untapped potential in provinces like
Guangdong and Yunnan, where geothermal exploration has already gained a strong foothold.

An exciting opportunity for unconventional geothermal energy use is the potential of using natural hot basement rocks that can be stimulated by fluids into enhanced/engineered geothermal system (EGS) and new technologies for drilling. These innovative ideas will allow breakthrough into tapping a potential new energy source for vast proliferation of geothermal deployment in China and other developing countries that can profit from these new ventures. After more than 30 years of exploration and research has so far been spent on advancing the technology, geothermal energy continues to be the yet unreachable silver bullet for our global sustainable energy supply.

Papers in this special issue will give an idea of the two meetings held in South China on the latest development concerning quantitative aspects of geothermal energy. They will show a broad spectrum of geothermal problems needed to be addressed with numerical simulations using different techniques.

The first gathering took place at the end of June in 2012 at China University of Geosciences in the city of Wuhan in Hubei Province. About 135 attendees partook in serious and enthusiastic discourse. Its success led to a second more focused workshop for two days at the end of June in 2013. This meeting was held under the auspices of the Guangdong Geological Survey in the metropolis of Guangzhou, Guangdong Province where there is great interest in exploiting geothermal energy. Around 100 people gathered. A field trip was taken on the third day to a geothermal drilling site at Yangjiang, Guangdong.

We hope that the contents of this special but eclectic volume in Journal of Earth Science will convey the excitement and enthusiasm of all those people who believe strongly in clean energy as the path to a brighter future in China, Asia and the rest of the world.

(C) China University of Geosciences and Springer-Verlag Berlin Heidelberg 2015 